\title{
AS AVALIAÇÕES EXTERNAS E O CURRÍCULO MÍNIMO DE GEOGRAFIA DO ESTADO DO RIO DE JANEIRO
}

\author{
The external evaluations and the minimum curriculum of geography of the state of Rio de \\ Janeiro \\ Suzana Campos Silva* \\ * Doutoranda em Geografia UFF/Professora SEEDUC-RJ - suzanarb2003@yahoo.com.br.
}

Resumo: 0 principal objetivo do trabalho aqui proposto é apresentar o modelo educacional criado na última década para o estado do Rio de Janeiro. Esse modelo, pautado em avaliações externas e na construção de um Currículo Mínimo, está relacionado aos planos de educação elaborados em escala nacional que estão atrelados a projetos internacionais para países "não desenvolvidos", que têm como uma de suas pautas a melhoria dos índices educacionais. A busca pela compreensão de tal "melhoria", sobretudo no que se refere aos impactos no ensino de Geografia, justifica a análise de políticas centradas em avaliações externas e no currículo.

Palavras-chave: Avaliações Externas; Currículo Mínimo; Ensino de Geografia.

\begin{abstract}
The main objective of the work proposed here is to present the educational model created in the last decade for the state of Rio de Janeiro. This model, based on external evaluations and the construction of a Minimum Curriculum, is related to education plans developed at the national scale that are linked to international projects for "Not developed", that have as one of their guidelines the improvement of educational indices. The search for understanding such "improvement", especially with regard to the impacts on Geography teaching, justifies the analysis of policies centered on external evaluations and the curriculum.
\end{abstract}

Key-words: External Evaluations; Minimum Curriculum; Teaching Geography.

\section{Introdução}

Para avaliar se os efeitos de políticas públicas educacionais aplicadas em um dado contexto socioespacial são positivos ou negativos é necessário que sejam observados seus impactos diretos no ambiente escolar, para que seja possível constatar a realidade por trás das estatísticas apresentadas pelos governos.

No estado do Rio de Janeiro é importante destacar a forma como os resultados das avaliações externas direcionaram as políticas educacionais construídas na última década. Os resultados do Índice de Desenvolvimento da Educação Básica (Ideb) para o Ensino Médio, divulgados em 2009, classificaram o estado na $26^{\underline{a}}$ posição, penúltima entre os vinte e seis estados brasileiros e o Distrito Federal. Essa colocação foi determinada a partir de um indicador que sintetiza informações de desempenho em exames padronizados (Prova Brasil que avalia nível de proficiência dos alunos em Língua Portuguesa e Matemática) com informações sobre rendimento escolar (taxa média de aprovação dos estudantes em cada etapa de ensino). Diante do resultado insatisfatório a prioridade da Secretaria de Estado de Educação (SEEDUC) passou a ser criar metas para alcançar melhores resultados.

Como uma das primeiras iniciativas o governo estadual decidiu criar o Sistema de Avaliação do 
Ensino do Rio de Janeiro (Saerj) e depois o Saerjinho. O Saerj contemplava as mesmas disciplinas da Prova Brasil e era aplicado para os anos finais do Ensino Fundamental e Médio ao final de cada ano letivo. Para auxiliar na eficácia dessa avaliação, como avaliação bimestral, foi criado o Saerjinho, que se estendia a outras disciplinas, incluindo Geografia. Essa avaliação era realizada por alunos do 5o , 6o e 9o anos do Ensino Fundamental e pelos três anos do Ensino Médio.

Para auxiliar nos resultados dessas avaliações, foi criado por uma equipe de especialistas o Currículo Mínimo, que gradativamente contemplou todas as disciplinas do ensino básico. Esse documento passou a ser amplamente utilizado pelos professores da rede estadual, em especial devido as pressões que as unidades escolares, sob vigilância da SEEDUC passaram a exercer sobre esses profissionais, que, em grande parte, foram responsabilizados pelo insucesso dos alunos da rede estadual nas avaliações externas nacionais.

\section{2 - Os sistemas de avaliação do estado do Rio de Janeiro}

Para adequar-se ao contexto neoliberal brasileiro pautado no atendimento de demandas externas definidas por instituições financeiras internacionais a partir do Consenso de Washington, realizado em 1989, o estado do Rio de Janeiro criou políticas educacionais centradas em avaliações externas e na construção de índices para medir, o que "dizia ser", a qualidade do ensino.

A partir dos anos 2000 uma série de políticas educacionais foram criadas para tentar deixar o estado do Rio de Janeiro em boa situação no cenário nacional. Mas, as mudanças mais significativas ocorreram com a eleição do governador Sérgio Cabral Filho (Partido do Movimento Democrático Brasileiro - PMDB), que esteve no cargo por dois mandatos consecutivos entre janeiro de 2007 e abril de 2014, quando renunciou ao cargo deixando em seu lugar o então vice-governador Luiz Fernando Pezão, também do PMDB.

O sistema de avaliação, uma das práticas obrigatórias do contexto escolar, a partir de então, passou a ser cada vez mais empregado como instrumento para auxiliar na precarização do ensino, utilizando-se o argumento de que todos teriam "igualdade de oportunidades", mas a metodologia e os instrumentos avaliativos garantiriam o processo discriminatório e seletivo. A avaliação passou a constituir-se em um instrumento para selecionar, classificar e rotular, fortalecendo o processo de exclusão dos alunos e garantindo a continuidade de uma estrutura econômica e social baseada em interesses políticos do sistema capitalista (LUCAS, 2000, p. 02).

Na tentativa de estabelecer um parâmetro para medir a educação a nível mundial foram criadas as avaliações externas, que trabalham para aprimorar os sistemas avaliativos em prol dos interesses capitalistas, seja para criação de trabalhadores adequados as demandas das empresas ou mesmo para atuação junto ao mercado editorial de livros didáticos. No caso brasileiro, em consonância com as exigências de organismos internacionais, foram criadas avaliações em escala nacional e para "treinar" os alunos para as provas os estados e os municípios desenvolveram sistemas próprios de avaliação.

$\mathrm{Na}$ busca de melhores resultados para os alunos da rede estadual na Prova Brasil, principal avaliação externa nacional aplicada para educação básica e que é utilizada para construção do Ideb, instituído em 2007, o governo estadual do Rio de Janeiro criou duas avaliações próprias: o Saerj e o Saerjinho.

O Saerj foi criado em 2008 e permaneceu em vigor até o início de 2016, ano em que não foi mais aplicado, devido as pressões exercidas pelos professores em greve e pelos estudantes que ocuparam dezenas de escolas. As provas do Saerj avaliavam os alunos do 5ㅜ e 9o anos do Ensino Fundamental e do 3o ano do Ensino Médio em Língua Portuguesa e em Matemática (RIO DE JANEIRO, 2011).

o Centro de Políticas Públicas e Avaliação da Educação (Caed), da Universidade Federal de Juiz de Fora, era a instituição que operacionaliza (elaborava e desenvolvia) o Saerj, assim como outros programas estaduais e municipais destinados a mensurar o rendimento de estudantes de escolas públicas ${ }^{1}$.

${ }^{1}$ Disponível em: <http://institucional.caed.ufff.br/quem-somos/>. Acesso em: 06 maio 2015.

ParaOnde!?, Porto Alegre, v.10, n.2, p.191-199, 2018. Edição Especial com artigos publicados originalmente na ENANPEGE http://seer.ufrgs.br/paraonde 
A partir de 2010, sob impacto dos resultados ruins do Ideb, que classificaram o estado do Rio de Janeiro na 26a posição, a SEEDUC acentuou as políticas educacionais para reverter tal situação. Por isso, foi dada maior ênfase ao Saerj, que passou a adequar-se cada vez mais aos moldes da Prova Brasil.

No ano de 2011, quando a SEEDUC já estava sob a gestão do economista e financista Wilson Risolia Rodrigues, que esteve na pasta entre seis de outubro de 2010 (ARAUJO, 2012, p. 53) e dezembro de 2014, como forma de aprimorar ainda mais o Saerj, foi criada a avaliação bimestral do Saerjinho que começou a ser aplicada a partir de abril e assim como a outra avaliação foi suspensa no início de 2016. Inicialmente, para "preparar" os alunos para o Saerj, eram aplicadas apenas provas de Matemática e Língua Portuguesa. A partir de 2013, as provas do Saerjinho passaram a conter questões de Geografia, Ciências Físicas e Biológicas, e em 2014 foram incluídos conteúdos de História. Sendo sempre mantido um número muito superior de questões para Matemática e Língua Portuguesa. A princípio realizavam a prova apenas os alunos do $5^{\circ}$ e $9^{\circ}$ anos do Ensino Fundamental e dos três anos do Ensino Médio, depois foram incluídos os alunos do 60 ano do Ensino Fundamental.

Para reforçar ainda mais o papel das avaliações externas a SEEDUC criou, também no ano de 2011, dentro do Plano de Metas estabelecido pelo Programa de Educação do Estado, o Índice de Desenvolvimento da Educação do Estado do Rio de Janeiro (Iderj). Muito similar ao Índice de Desenvolvimento da Educação Básica (Ideb), o Iderj traduzia o fluxo e o desempenho em um número de 0,0 (zero) a 10,0 (dez) ${ }^{2}$. A criação desse índice, que estabelecia as metas anuais que deveriam ser alcançadas, foi acompanhada da criação do Iderjinho, que estabelecia as metas bimestrais.

A criação desse sistema composto por avaliações externas e índices, segundo as concepções de Gaudêncio Frigotto (2010) e István Mészáros (2008), é mais um instrumento do capitalismo para fazer da escola um local útil para a "criação" de trabalhadores adequados aos novos postos de trabalho. 0 trabalhador de hoje tem que ser capaz de dominar as mais modernas tecnologias, assim como de oferecer respostas rápidas diante dos desafios impostos pela função que exerce. Portanto, o aluno deve ser capaz de expor em avaliações tudo o que aprendeu ou que espera-se que tenha aprendido. Caso isso não funcione há algum problema que precisa ser corrigido e cabe a escola resolver antes que esse aluno, futuro trabalhador, chegue a empresa capitalista.

Essas ideias estão postas por István Mészáros (2008, p. 15) quando afirma que:

A educação, que poderia ser uma alavanca essencial para a mudança, tornou-se instrumento daqueles estigmas da sociedade capitalista: fornecer os conhecimentos e o pessoal necessário à maquinaria produtiva em expansão do sistema capitalista, mas também gerar e transmitir um quadro de valores que legitima os interesses dominantes. Em outras palavras, tornou-se uma peça do processo de acumulação de capital e de estabelecimento de um consenso que torna possível a reprodução do injusto sistema de classes. Em lugar de instrumento da emancipação humana, agora é mecanismo de perpetuação e reprodução desse sistema.

A escola planejada no contexto da rede estadual do Rio de Janeiro tornou-se mais um instrumento para manutenção dos interesses da sociedade capitalista. Projeto esse que manifestou-se desde a escala nacional pela ação e controle promovidos pelo Banco Mundial sobre as políticas educacionais para todo o Brasil. Para Gaudêncio Frigotto (2010) esse é o viés improdutivo da escola, que serve para manter a própria produtividade do sistema capitalista, ao manter o domínio das classes dominantes e a desqualificação do conhecimento. A escola de hoje ajusta-se muito mais às necessidades de quantificação para obter bons resultados em avaliações externas do que para promover um ensino capaz de formar cidadãos conscientes de seu papel no mundo.

0 questionamento apresentado aqui não direciona-se ao ato de avaliar, mas sim a forma como as avaliações têm sido inseridas no contexto escolar. "A avaliação é um suporte importante para o processo de ensino-aprendizagem, permitindo a análise da ação educativa num processo contínuo, dando subsídios ao redimensionamento da prática pedagógica" (COPATTI, 2014, p. 168). Nessa situação a preocupação está no que o aluno aprendeu e não na mensuração de resultados. Não apenas

2 Disponível em <http://www.rj.gov.br/web/seeduc/exibeconteudo?article-id=843535>. Acesso em: 12 de maio de 2015.

ParaOnde!?, Porto Alegre, v.10, n.2, p.191-199, 2018. Edição Especial com artigos publicados originalmente na ENANPEGE http://seer.ufrgs.br/paraonde 
nas aulas de Geografia, mas em todas as disciplinas, o que deve ser estimulado é a autonomia intelectual de cada aluno. Não basta que o aluno tire notas excelentes e seja aprovado, se o que ele fez foi apenas reproduzir o que está exposto em livros e na fala do professor.

É necessário que o aluno seja capaz de perceber as relações entre diferentes fenômenos que ocorrem nas mais diversas escalas, e mais, que perceba o quanto ele e o seu entorno estão inseridos no mundo e fazem parte de uma totalidade. Por isso, no que se refere à Geografia, segundo Copatti (2014, p. 179):

a avaliação precisa considerar os valores culturais, ou seja, não há como homogeneizar os educandos para que aprendam e constituam valores e sentimentos de maneira igualitária, pois cada indivíduo traz consigo suas vivências, suas histórias de vida e a cultura, herdada das experiências no contexto onde vive.

A cultura de cada grupo deve estar presente nas aulas, para que sejam percebidos os diferentes modos de vida e principalmente para que seja criado o respeito à diversidade. As aulas de Geografia devem motivar os alunos a terem pensamentos diversos, evidenciando que pessoas e grupos são diferentes e que por isso devem ser respeitados em suas particularidades. 0 momento da avaliação deve refletir isso, apontando para aspectos específicos das experiências cotidianas do grupo de alunos no qual está sendo inserida. Por fugir a essas ideias as avaliações externas recebem tantas críticas, já que priorizam a homogeneização em detrimento da diversidade inerente ao ambiente escolar. No que se refere às avaliações externas aplicadas na rede estadual de ensino do Rio de Janeiro, contudo, o que era exigido dos alunos era exatamente que fossem capazes de responder a questões, e de certo modo, que decorassem as respostas ou padrões de respostas das perguntas que poderiam aparecer nas provas do Saerj e do Saerjinho, o mesmo método é aplicado constantemente nas escolas de todo o país para as avaliações em escala nacional como a Prova Brasil e o Enem.

Os conteúdos e forma como as questões de Geografia do Saerjinho foram construídas expõem de forma clara que a preocupação com o aprendizado era secundária para a SEEDUC. $\mathrm{Na}$ maioria das questões havia um alto grau de "facilidade", o que expunha o desejo da secretaria para que o número de acertos fosse elevado independente do nível de conhecimento dos alunos. Do ponto de vista dos conceitos geográficos, por exemplo, havia nessas provas o uso excessivo da divisão macrorregional feita pelo IBGE, sem que fossem ao menos citadas outras formas de regionalização. 0 mesmo ocorria com a regionalização do mundo em continentes que não deixava margens para analisar o mundo de outras maneiras. Nesses casos as provas reproduziam o que estava descrito na Matriz de Referência e no Currículo Mínimo - uma visão fragmentada de Geografia, que não permitia estabelecer relações entre os elementos estudados, tanto que nas provas as questões sequer tinham um encadeamento de ideias.

Para compreender como o Currículo Mínimo funcionava em conjunto com esse sistema de avaliação externa, a seguir estão descritas algumas características desse documento.

\section{3 - 0 Currículo Mínimo de Geografia}

Inserido no campo pedagógico, o termo currículo passou por diversas definições ao longo da história da educação. Tradicionalmente esse significou uma relação de matérias/disciplinas com seu corpo de conhecimento organizado numa sequência lógica, com o respectivo tempo de cada uma (grade ou matriz curricular). Essa conotação guarda estreita 
relação com "plano de estudos", tratado como o conjunto das matérias a serem ensinadas em cada curso ou série e o tempo reservado a cada uma $^{3}$.

Para Ana Claudia Ramos Sacramento (2007, p. 80) "os currículos têm por objetivo orientar a construção do conhecimento escolar" através do diálogo que estabelecem entre a escola e os demais agentes envolvidos no processo de ensino. É por meio deles que a teoria e a prática são conduzidos. "A forma como se produz o currículo está relecionado ao tipo de aluno que está se formando, qual o objetivo da formação docente e o ideal de escola".

Segundo Gimeno Sacristán (2000, p. 44) "a preocupação pelos temas estritamente curriculares surge em parte por conveniências administrativas, antes que por uma necessidade intelectual". Para o autor:

Antes de ser um campo que prolonga preocupações da psicologia, da filosofia, etc. é uma responsabilidade "profissional" da administração e isso explica o poderoso domínio que sobre ele estabelecem as noções e mecanismos de racionalização utilizados pela gestão científica (SACRISTÁN, 2000, pp. 44-45).

Os instrumentos de implementação e controle do currículo utilizados atualmente são apenas novas formas de fazer desse documento algo útil para atender as necessidades do capitalismo. Na prática, a tecnocracia, ainda dominante no mundo educativo, tem priorizado evitar em suas coordenadas o discurso filosófico, político, social e até pedagógico sobre o currículo. Esse ainda é um objeto manipulado tecnicamente, evitando elucidar aspectos controvertidos, sem discutir o valor e significado de seus conteúdos. 0 que produz uma tradição de pensamento e pesquisa psicológica e pedagógica acultural e acrítica (SACRISTÁN, 2000, p. 47).

Dentro dessa perspectiva tecnicista ou neotecnicista, no pacote de medidas adotado pelo secretário Wilson Risolia Rodrigues, destaca-se o Currículo Mínimo, implementado como documento oficial da rede estadual para os anos finais do Ensino Fundamental e para o Ensino Médio regular em 14 de fevereiro de 2011 e em vigor até o presente. O documento priorizou, inicialmente, seis disciplinas: Língua Portuguesa/Literatura; Matemática; História; Geografia; Sociologia e Filosofia (QUIRINO et al., 2011). Para o ano de 2012 foi feita a revisão dos conteúdos das seis disciplinas mencionadas e elaborado o Currículo Mínimo de outras seis disciplinas: Ciências/Biologia; Física; Química; Língua Estrangeira; Educação Física e Arte. Assim, a partir de 2012, as escolas estaduais passaram a utilizar esse currículo para as doze disciplinas da Base Nacional Comum dos Anos Finais do Ensino Fundamental e Médio Regular (RIO DE JANEIRO, 2012, p. 2).

o Currículo Mínimo que foi enviado as escolas no início do ano letivo de 2011 trazia em seu subtítulo a frase "uma proposta em discussão", contudo esse passou por um rápido processo de elaboração, que contou com uma pequena participação dos professores em poucos encontros presenciais e contribuições via página eletrônica da SEEDUC, no período entre o final de dezembro de 2010 e o início de janeiro de 2011 quando foi divulgado o material e aberta a possibilidade de participação e contribuição dos professores. 0 fato de terem sido promovidos encontros com os professores da rede, no entanto, foi apenas uma estratégia utilizada para garantir legitimidade ao documento, já que as opiniões e sugestões que deveriam ter o intuito de aprimorar e avançar no debate não foram respeitadas. Ao observar a versão definitiva do Currículo Mínimo de Geografia, que chegou as escolas no ano de 2012, é possível constatar que essa é apenas um "resumo" do documento de 2011, os conteúdos apresentados mantiveram-se na mesma sequência, apenas foi retirado o que a equipe responsável considerou desnecessário, como por exemplo, instruções didáticas. 0 que comprova que a consulta aos professores foi apenas uma forma de legitimar o documento.

Os argumentos da SEEDUC são de que o Currículo Mínimo representa apenas uma orientação e que os professores devem adequá-lo à diferentes realidades. Mas, esse era o documento que orientava as Matrizes de Referência para as provas do Saerj e Saerjinho, embora muitas vezes as matrizes

3 Descrição elaborada por Solange Aparecida Zotti.

Disponível em <http://www.histedbr.fe.unicamp.br/navegando/glossario/verb_c_curriculo.htm>. Acesso em: 18 de outubro de 2015 .

ParaOnde!?, Porto Alegre, v.10, n.2, p.191-199, 2018. Edição Especial com artigos publicados originalmente na ENANPEGE http://seer.ufrgs.br/paraonde 
também não estivessem totalmente adequadas aos conteúdos indicados pelo Currículo Mínimo.

0 texto introdutório do Currículo Mínimo expõe que esse é um documento que serve como referência a todas as escolas estaduais, apresentando as competências, habilidades e conteúdos básicos que devem estar nos planos de curso e nas aulas (QUIRINO et al., 2011). Para a SEEDUC, o Currículo Mínimo tem por finalidade:

Orientar, de forma clara e objetiva, os itens que não podem faltar no processo de ensino aprendizagem, em cada disciplina, ano de escolaridade e bimestre. Com isso, pode-se garantir uma essência básica comum a todos e que esteja alinhada com as atuais necessidades de ensino, identificadas não apenas nas legislações vigentes, Diretrizes e Parâmetros Curriculares Nacionais, mas também nas matrizes de referência dos principais exames nacionais e estaduais (RIO DE JANEIRO apud QUIRINO et al., 2011).

Desse modo, o principal objetivo para formulação desse currículo foi atender as demandas vigentes, sobretudo no que se refere à compatibilidade de conteúdos e a adequação às avaliações externas, com foco especial para a melhoria do Ideb.

Para Quirino et al. (2011) com a criação desse currículo a autonomia pedagógica em sala de aula passou a enfrentar mais obstáculos impostos "de cima para baixo", pois para que os alunos obtivessem bons resultados nas avaliações externas os professores foram induzidos a aplicarem o currículo. 0 que foi reforçado pelo sistema de bonificação por resultados, programa meritocrático desenvolvido pela SEEDUC para que os ganhos salariais estivessem atrelados ao aumento do número de aprovações, redução do índice de evasão, entre outros fatores.

$\mathrm{Na}$ prática esse currículo serviu mais para alimentar os interesses do governo vigente do que para orientar e estimular a construção do conhecimento no ambiente escolar. A partir da observação do documento de Geografia é possível comprovar essa afirmação.

Segundo o texto introdutório do Currículo Mínimo os referenciais para o ensino da disciplina são:

A análise escalar e as representações gráficas e cartográficas como um instrumental para a compreensão dos fenômenos e processos geográficos em todos os níveis de ensino; a visão da globalização como processo; a análise ambiental permeando todo o currículo; as possibilidades de estabelecer um diálogo entre as diferenças, valorizando a diversidade cultural; e a problematização das questões geográficas referentes ao Estado do Rio de Janeiro (RIO DE JANEIRO, 2012).

O texto cita a importância da análise de diferentes escalas, assim como defende Yves Lacoste (1988) através da espacialidade diferencial, destaca o processo atual de globalização, as questões ambientais e a diversidade cultural. Esse resumo dos objetivos aponta para discussões inseridas dentro da perspectiva crítica, contudo, a forma como se estruturam as competências e habilidades no interior do documento denuncia que esse é apenas um discurso limitado a introdução.

Na observação da introdução, de apenas meia página, é possível perceber que não são citadas de forma clara quais foram as concepções de Geografia utilizadas. 0 texto apenas menciona que foi possibilitada a inserção de diferentes linhas teóricas e abordagens. Mas, não há nenhuma exemplificação de quais são essas linhas. Para Ariovaldo Umbelino de Oliveira (1999, p. 48) não eleger uma concepção de Geografia para dar sustentação e consistência epistemológica, em nome da pluralidade, faz com que o ecletismo apareça como concepção dominante.

No último parágrafo desse texto introdutório defende-se a autonomia para que o professor aplique o currículo da forma que achar adequada, mas, na prática esse tem que aplicar os conteúdos no momento estabelecido pelo currículo para que os alunos realizem o Saerjinho. Ao final de cada bimestre o professor deve ainda informar durante o lançamento de notas online que etapas do currículo conseguiu cumprir. Para garantir essa aplicação do Currículo Mínimo em 14 de fevereiro de 2013 a SEEDUC publicou a resolução no 4.866, que dispõe sobre a implantação e acompanhamento do currículo. Entre outras coisas, o documento afirma em seu artigo segundo que o cumprimento do Currículo Mínimo é obrigatório em sua totalidade, ainda que se "respeite a autonomia" do professor 
para possíveis ajustes 4 .

0 modo como as atuais políticas curriculares têm sido direcionadas às avaliações externas é questionado por Philippe Perrenoud (2003). Para o autor, o mais importante é que "o currículo tenha precedência e se fundamente naquilo que pareça essencial para ensinar e aprender, em vez de fundamentar-se na obsessão de avaliar de modo preciso ou na preocupação de fazer boa figura diante de uma concorrência que passa por tantas mediações".

Para tentar fazer essa "boa figura" nas avaliações o documento curricular de Geografia mantém em seu interior o mesmo "ecletismo" indicado na introdução. Mas, há certa polaridade dividida entre a Geografia Tradicional e a Geografia Crítica, que embora sejam antagônicas, misturam-se como se fossem complementares no documento. Assim, o documento curricular, ao invés de contribuir para métodos de ensino eficientes e adequados as diferentes realidades escolares, mantêm-se como uma proposta sem fundamentação teórica e metodológica, impedindo a construção da qualidade do ensino de que tanto fala a SEEDUC.

0 documento estrutura-se com apenas um foco para cada bimestre com habilidades e competências necessárias para atingir cada um. Ao longo dos quatro bimestres, os focos do $6^{0}$ ano, por exemplo, estão no conceito de espaço, mas tal conceito não é tratado de forma crítica como sugeria o movimento de Renovação da Geografia construído a partir da década de 1970. No 7º ano há uma divisão muito clara dos focos dos bimestres segundo a sequência francesa clássica N-H-E (Natureza Homem - Economia) 5 . 0 conceito que perpassa os focos é o de região, central para a Geografia Tradicional e muito útil para os interesses do Estado durante muitas décadas, reforçando as potencialidades regionais através de aspectos naturais, humanos e econômicos. Já no 8o ano ao mesmo tempo em que opta-se por habilidades e competências com claro foco na Geografia Crítica, mantém-se o foco na divisão regional, tanto para discutir a base física quanto aspectos relacionados a economia e a cultura do continente americano. Na organização do currículo do 90 ano aparecem termos utilizados pela Geografia Crítica, mas o que prevalece é a estrutura N-H-E para tratar dos continentes. Para o Ensino Médio, embora também apareçam temas típicos da Geografia Crítica, montou-se uma estrutura geral que fragmenta o arquétipo N-H-E nos três anos, alocando a natureza no $1^{\circ}$ ano e os aspectos humanos e econômicos no $2^{\circ}$ e $3^{\circ}$ anos.

De modo geral, o que é revelado com a observação do Currículo Mínimo é uma fragmentação da ciência geográfica fazendo com que o ensino da disciplina de Geografia seja, muitas vezes, reproduzido dessa forma.

\section{4 - Considerações finais}

As avaliações externas e as reformas curriculares que se tornaram tão centrais para educação brasileira tiveram grande impacto sobre a educação aplicada no estado do Rio de Janeiro na última década. 0 que mais se destaca nesse conjunto de políticas educacionais é o fato de terem sido construídas fora do espaço escolar. 0 maior foco na melhoria das notas do estado no Ideb fez com que se construísse um ensino pautado em resultados e índices, o que não trouxe reflexos para a qualidade do ensino que se oferece para a população.

Uma rápida observação dos conteúdos das avaliações do Saerjinho de Geografia permite concluir que essas provas não permitiam o desenvolvimento do conhecimento necessário para cada ano de escolaridade, mas contribuíram para a acentuação do peso das notas atribuídas as avaliações construídas fora do espaço escolar.

\footnotetext{
4 Disponível em <http://mminerva.blogspot.com.br/2013/02/resolucao-seeduc-n-4866-de-14-de.html>. Acesso em: 30 de maio de 2015.

\begin{abstract}
5 É a ideia do homem excluído da natureza quando esta é reduzida a uma coisa física. Um homem que não está situado na natureza e que também não está situado na sociedade. "Fica, assim, solto no campo representacional para a captura pelos discursos que vão se sucedendo no tempo (...). Então, surge um homem transformado em estatística tanto pelo lado da produção quanto pelo dado do consumo, num mundo da natureza transformada em estoque de recursos naturais. Homem e natureza jogados numa mesma sorte" (MOREIRA, 2011, p. 77).
\end{abstract}

ParaOnde!?, Porto Alegre, v.10, n.2, p.191-199, 2018. Edição Especial com artigos publicados originalmente na ENANPEGE http://seer.ufrgs.br/paraonde 
O Currículo Mínimo, como parte desse pacote de políticas educacionais, também contribuiu para manter a Geografia como uma disciplina pouco propositiva, ao apresentar-se como um documento sem estrutura metodológica e conceitual, dificultando, por isso, o estímulo a construção de conceitos e métodos da análise geográfica que permitem criar nos alunos uma melhor visão do mundo e capacidade de mobilizar sua transformação.

A análise dessas duas políticas educacionais apontou para a reprodução de uma visão fragmentada da Geografia, distanciada da realidade dos alunos, que por isso demanda um grande esforço de resistência e luta.

\section{Referências Bibliográficas}

ARAUJO, T. S. O. de. Eu penso Educação como um negócio: a meritocracia nas políticas educacionais do governo Sérgio Cabral Filho. Dissertação (Mestrado Profissionalizante em Educação Profissional em Saúde). Fundação Oswaldo Cruz, Escola Politécnica de Saúde Joaquim Venâncio, Rio de Janeiro, 2012.

COPATTI, CARINA. Avaliação escolar em Geografia: contribuições da Educação Estética nesse processo. In Revista Olhares, São Paulo, v. 2, p. 168-193-193, 2014.

FRIGOTTO, Gaudêncio. A produtividade da escola improdutiva. 9a edição. São Paulo: Editora Cortez, v. 1.263p. 2010.

LACOSTE, Yves. A geografia - isso serve, em primeiro lugar, para fazer a guerra. 3a edição, Campinas: Papirus, 1988.

LUCAS, Rosa Elan Antória. A avaliação no processo ensino/aprendizagem da Geografia. In Boletim Gaúcho de Geografia, Porto Alegre, julho, 2000.

MÉSZAROS, István. A educação para além do capital. 2ª edição. São Paulo: Boitempo, 2008.

MOREIRA, R. Para Onde Vai o Pensamento Geográfico? São Paulo: Contexto, 2011.

OLIVEIRA, A. U. Geografia e Ensino: Os Parâmetros Curriculares Nacionais em Discussão In CARLOS, A. F. A.; OLIVEIRA, A. U. (Org.). Reformas no Mundo da Educação - Parâmetros Curriculares e Geografia, São Paulo: Contexto, 1999.

PERRENOUD, Philippe. Sucesso na Escola: Só o currículo, nada mais que o currículo! In Cadernos de Pesquisa (Fundação Carlos Chagas), no 119, julho, pp. 7-26, 2003.

QUIRINO, M. J. S. O.; PEREIRA, C. A. S. ; LEAL, C. A. ; OLIVEIRA, V. L. Políticas Curriculares: Uma Breve Crítica ao Currículo Mínimo Implantado no Estado do Rio de Janeiro. In Anais do VIII ENPEC - Encontro Nacional de Pesquisa em Educação em Ciências e I CIEC - Congreso Iberoamericano de Investigación en Enseñanza de las Ciencias, Campinas, 2011.

RIO DE JANEIRO. Currículo Mínimo 2011. In Secretaria de Estado de Educação, Rio de Janeiro, 2011. Disponível em <http://www.rj.gov.br/web/seeduc/exibeconteudo?article-id=374742>. Acesso em: 11 de dezembro de 2013.

Currículo Mínimo 2012. In Secretaria de Estado de Educação, Rio de Janeiro, 2012. Disponível em <http://www.conexaoprofessor.rj.gov.br/curriculo_aberto.asp>. Acessado em: 11 de dezembro de 2013. 
SACRAMENTO, A. C. R. O currículo na construção do conhecimento geográfico: um estudo da ação docente de duas escolas estaduais de São Paulo. Dissertação de mestrado, Universidade de São Paulo, São Paulo, 2007.

SACRISTÁN, J. Gimeno. O Currículo: uma reflexão sobra a prática. 3aㅗ ed. Porto Alegre: Artmed, 2000. 